\title{
A new route for the synthesis of La-Ca oxide supported on nano activated carbon via vacuum impregnation method for one pot esterification-transesterification reaction
}

\begin{abstract}
Advanced carbon nanorod promoted binary $\mathrm{CaO}-\mathrm{La} 2 \mathrm{O} 3$ system with improved physical properties, tailored surface morphology and chemistry were developed in vacuumimpregnating methods. The nanostructured catalyst (CaO-La2O3/AC nanocatalyst) was prepared to convert high FFA waste cooking oil into biodiesel via one step esterificationtransesterification reaction. The novel catalyst was characterized by FTIR, SEM, XRD, TGA, BET, TPD-CO2 and TPD-NH3. The high catalytic activity of the nanocatalyst was mainly depends on the high acid and basic density of active sites that contributed from the synergic effect between mesoporous carbon and binary metallic system, which allowed more occurrence of simultaneous esterification-transesterification process of high FFA waste oil without additional pretreatment step. Result showed maximum $98.6 \pm 0.5 \%$ with acid value $0.4 \pm 0.5 \mathrm{mg} \mathrm{KOH} / \mathrm{g}$ of triglyceride conversion under optimal condition at $3 \%$ of catalyst, methanol:oil ratio of $16: 1,100{ }^{\circ} \mathrm{C}$ within $4 \mathrm{~h}$ of reaction. Furthermore, bi-metallic catalyst with stable carbon nanorod support capable to maintained high reusability with high FAME yield $(>98 \%)$ with low acid value $(<0.5 \mathrm{mg} \mathrm{KOH} / \mathrm{g})$ for 5 cycles.
\end{abstract}

Keyword: Carbon nanorod; Lanthanum oxide; Waste cooking oil; Acid-base catalyst; Biodiesel 